\title{
Um sujeito ocultado: trabalhadores e regime militar no Brasil
}

A hidden subject: workers and military regime in Brazil

\author{
Marco Aurélio Santana*
}

Resumo- $O$ artigo reflete sobre a trajetória dos trabalhadores brasileiros e suas entidades representativas durante o Regime Militar (19641985), bem como sobre as visões políticas e acadêmicas sobre a atuação dos mesmos no período. Neste sentido, indica o que seria um ocultamento sobre as efetivas atividades desenvolvidas por tais atores, seja no sentido da resistência ao regime militar, seja no que diz respeito ao apoio ao mesmo. Aponta-se o que poderiam ser vetores futuros de pesquisa acerca da temática.

Palavras-chave: trabalhadores; trabalho; movimento sindical; partidos de esquerda; ditadura militar.

\begin{abstract}
The article reflects on the trajectory of Brazilian workers and their representative bodies during the military regime (19641985), as well as the political and academic views on the work of the same period. In this regard, indicating that would be effective concealment of the activities performed by such players, either in the sense of resistance to the military system or supporting it. It is pointed out what could be the future research vectors on the theme.

Keywords: workers; labour; trade unions; left wing parties; military dictatorship
\end{abstract}

\section{Da época de ouro ao sujeito oculto}

A década de 1950 marca um período de extrema importância para os trabalhadores brasileiros. O movimento sindical, capitaneado pela aliança das militâncias do Partido Comunista Brasileiro (PCB) e do Partido Trabalhista Brasileiro (PTB), logrou grande avanço em termos de organização e mobilização, o que resultou em uma forte participação dos trabalhadores no seio da sociedade e na vida política nacional. Pode-se dizer que se viveu um período de ouro na história deste movimento.

\footnotetext{
* Professor Associado de Sociologia do Departamento de Sociologia (DS) e do Programa de Pós-graduação em Sociologia e Antropologia da Universidade Federal do Rio de Janeiro (PPGSA-UFRJ). Correspondência: Universidade Federal do Rio de Janeiro, Instituto de Filosofia e Ciências Sociais. Largo de São Francisco, 1, Sala 418 - Centro - Rio de Janeiro, RJ. CEP: 20051-070. E-mail: <marcosilvasantana@gmail.com>
} 


\section{Revista pll pavtg}

\} UM SUJEITO OCULTADO - SANTANA, M. A. \}

Malgrado isso, após mais de uma década desse intenso crescimento e atividade, toda a estrutura organizacional dos trabalhadores brasileiros, na base e na cúpula, foi duramente atingida pelo Golpe de Estado de 1964. Os golpistas apresentavam como uma das suas justificativas exatamente impedir a implantação de uma "república sindicalista" no país. A intervenção nas entidades, a prisão e perseguição de lideranças e militantes, bem como a desestruturação do trabalho nos sindicatos e nas fábricas, desmontaram atividades que levariam bastante tempo para ser recompostas enquanto tal. Em termos do movimento operário, o que restou, como tradicionalmente ocorria em períodos como este, foi o trabalho pequeno e silencioso no chão de fábrica e tentativas de avanços sutis na estrutura social. Era preciso recompor forças e somar esforços para enfrentar a ditadura.

No que diz respeito aos grupos militantes, a implantação do regime militar abriu, no seio da esquerda em geral, e no interior do até então partido hegemônico da esquerda, o PCB, em particular, um duro e sério debate acerca dos caminhos percorridos antes e depois do Golpe. Como se havia chegado até ali? Como explicar tão fragorosa derrota? Quem seriam os responsáveis? Da crítica e autocrítica resultou a aparição de uma série de outros grupos e concepções dos novos rumos a serem trilhados. A terra entrara em transe.

O PCB, diante das posturas assumidas pré e pós-Golpe (com sua política de alianças com a burguesia nacional e de frente pela democracia), era responsabilizado e colocado em uma posição como que à margem do processo de luta das esquerdas. Enquanto o partido clamava pela organização de base e pela via pacífica de luta contra a ditadura e pela democracia, entravam em cena as ações armadas enquanto opção de oposição ao regime. Um dado importante é que, contrabalançando a opção quase geral dos grupos de esquerda pela luta armada, o PCB optou por uma tentativa de penetrar na estrutura sindical, que dominara no pré-1964 e de onde havia sido defenestrado. E é a partir daí que balizará suas ações até o fim do período.

Deve-se dizer que muitas das críticas sobre o período pré-Golpe e de seus resultados pós-Golpe foram construídas no interior do próprio Partido. Para alguns de seus setores, ele havia sido "reformista" em demasia. Para outros, "radicalizado" demais. Assim, uma década tão importante para a história dos trabalhadores brasileiros ficou órfã. Como um anjo caído do processo. Uma década, cujas experiências sindicais não deveriam ser repetidas; antes, criticadas.

No que diz respeito ao mundo do trabalho, logo após o Golpe vão se radicalizar algumas tendências em termos de economia, que produzirão uma intensa transformação na face do país como um todo, e principalmente de sua classe operária. A intensificação da introdução de plantas industriais modernas e sua concentração geográfica (processo que se inicia em fins dos anos 1950) vão possibilitar o surgimento do que se conven- 


\section{ReVistg all PaUtg}

\} UM SUJEITO OCULTADO - SANTANA, M. A. \}

cionou chamar de "nova classe operária". Ainda que não exclusivamente, serão estes os atores que despontarão mais tarde auxiliando na crise final da ditadura militar.

A história dos trabalhadores brasileiros e de suas organizações tem sido alvo, em seus mais diferentes períodos, de já farta literatura. Contudo, deve-se dizer que muito ainda há para ser feito quando se trata das análises dos movimentos dos trabalhadores no período da ditadura militar, sejam eles os mais subterrâneos até aqueles de maior aparição na cena pública.

Por diversos - e compreensíveis - fatores, o período de abertura e redemocratização recebeu uma atenção muito maior que outros, a contar do marco da greve de 1978 no ABC paulista e o posterior ressurgimento, a céu aberto, do movimento dos trabalhadores. Desbalanceado por visões influenciadas pelo debate político, produziu um conjunto de visões sobre a história do trabalho no período que precisam ser revisitadas. Daí ter se criado o mito, um tanto em piada, mas que muitos acreditaram, de que, em termos de trabalhadores (greves, comissões de fábrica etc.), "tudo começou em 1978". Cabe agora um esforço de pesquisa mais sistemático e aprofundado sobre o período que vai de 1964 até 1978 .

Sempre que se constrói uma retrospectiva ou comemora-se uma efeméride, obviamente, faz-se uma escolha. Fatos são selecionados como característicos desse ou daquele momento. Acaba-se mesmo firmando certas ideias e/ou, na passagem do tempo, destituindo outras.

Quando das atividades realizadas dentro e fora das universidades brasileiras acerca dos 40 anos do golpe civil-militar, viu-se uma importante e densa discussão sobre temas, tais como militares, luta armada, imprensa, estudantes, parlamento etc. Sobressaia a quase completa ausência dos trabaIhadores e de seus sindicatos como tema dos debates. Talvez alimentada ainda pela ideia corroída da "culpa" dos mesmos por suas ações no pré1964 ou pela distorcida visão de que eles nada teriam feito no pós-Golpe. Esquematicamente, teriam se "equivocado" no pré-1964, sido "derrotados" em 1964 e ficado "imobilizados" no pós-1964.

O dado é que se conseguiu fazer uma releitura dos acontecimentos sem que um de seus principais atores estivesse presente de forma mais efetiva. Este não foi o caso, agora nos 50 anos, quando a temática foi inserida em vários seminários e publicações. De todo, antes uma classe à qual todos queriam se associar, passava a uma "classe fantasma" da qual se queria distanciar ${ }^{1}$.

\footnotetext{
${ }^{1}$ Aproprio-me aqui, adaptando ao nosso caso, do uso que fazem Beaud e Pialoux (2009) da ideia de "classe fantasma". Para eles, houve a transformação da classe operária francesa em uma "classe fantasma" (título do livro de Jean-Pierre Levaray, citado por Beaud e Pialoux), na medida em que, em duas décadas, entre os anos 1960 e 1980, a classe operária francesa teria passado de centro das atenções político-sociais para o quase esquecimento. No entanto, para os autores, apesar desse obscurecimento no espaço público, a questão operária continuaria mais do que nunca atual.
} 


\section{Revista pll pavtg}

\} UM SUJEITO OCULTADO - SANTANA, M. A. \}

A conjunção de processos políticos, sociais e intelectuais produziu todo um ocultamento da participação dos trabalhadores e de suas entidades em um período histórico tão importante. Diante disso, somando-se a dificuldades com acervos, ficou sempre muito difícil identificar e analisar o papel que os trabalhadores desempenharam ativa e efetivamente naquela conjuntura.

Se muito já foi feito sobre o período do Golpe e da Ditadura Militar acerca de outros temas e atores sociais ${ }^{2}$, pode-se dizer que muito há para se fazer no que tange aos impactos do regime pós-1964 sobre o trabalho e os trabalhadores brasileiros. A forte repressão não facilitou acessos às fontes, que sobraram em meio a muitas que foram destruídas. Só mais recentemente alguns acervos estão sendo abertos, o que já tem favorecido uma série de achados acerca de outros setores sociais, embora ainda não tenham sido explorados plenamente no que tange ao mundo do trabalho e dos trabalhadores. Da mesma forma, sob a repressão, a dificuldade de produção e análise de documentação oral não esteve mais facilitada, só se tornando possível nos momentos mais finais do regime de exceção.

É por isso que os trabalhos desenvolvidos, por exemplo, pela Comissão de Anistia e pela Comissão Nacional da Verdade - bem como por outras comissões setoriais - têm ajudado e ainda ajudarão muito no sentido do desvelamento da participação dos trabalhadores de forma efetiva nesta quadra histórica. Impressiona - ainda que já fosse esperado - o número de trabalhadores e sindicalistas envolvidos, por exemplo, nos processos de anistia e nos depoimentos das variadas comissões da verdade pelo país. Isso só reforça a ideia da importância destes trabalhadores durante o regime militar.

\section{Algumas linhas e vetores analíticos}

Quando se trata das análises dos movimentos sobre trabalhadores no período da Ditadura Militar, sentimos limitações similares encontradas quanto às fontes. Acreditamos não ser o espaço aqui de fazer uma análise exaustiva de todos os estudos efetivados acerca da questão. Contudo, podese indicar que não são muitas as análises que se debruçaram sobre esse tema especificamente, comparando-se a outros períodos. Creio que isso se deve, entre outras coisas, tanto às dificuldades com as fontes trazidas pelo regime de exceção, quanto às orientações de muitos analistas que acabaram, talvez por críticas ao movimento operário, mirando muito mais em outros movimentos, como o estudantil e o da esquerda armada, por exemplo.

\footnotetext{
${ }^{2}$ Ver, por exemplo, entre outros, Krischke (1982), Aarão Reis F.o (1986); Gorender (1987); Figueiredo (1993); Soares e D'Araujo (1994), Toledo (1997); Aarão Reis F.o (1997); Aarão Reis F.o (2000); Fico (2000); Aarão Reis F.o , Ridenti, Motta (2004), Araújo, Fico, Martins, Souza, Quadrat (2004); Ferreira e Aarão Reis Fo (2007) e Fico e Araújo (2009).
} 


\section{ReVistg all paUtg}

\} UM SUJEITO OCULTADO - SANTANA, M. A. \}

Tomadas em seu conjunto, podemos identificar algumas linhas seguidas no interior das pesquisas e da literatura nas ciências sociais ${ }^{3}$. Alguns setores da literatura se dedicaram, no próprio período da ditadura, muito mais a investigar as formas de orientação e organização dos trabalhadores antes do golpe de 1964, e que pudessem esclarecer também sua postura frente à implantação do regime militar. Muitos desses trabalhos são duramente críticos das ações e orientações do PCB (WEFFORT, 1978). São quase inexistentes aqueles que tratam do período imediato ao Golpe de Estado até as greves de Contagem e Osasco de $1968^{4}$ (COUTO, 2003). Os estudos sobre estes movimentos abrirão um flanco interessante de análise, aí já sobre o pós-1964 (WEFFORT, 1972).

Uma linha bastante interessante, mas pouco perseguida posteriormente, trata da estrutura e burocratização dos sindicatos durante o período (MARTINS, 1979). Outra linha que visou entender a vida e as ações dos trabalhadores durante a ditadura militar teve a ver com estudos mais quantitativos e sociológicos no sentido de, a partir de determinados perfis sociais, entender as atitudes operárias no bojo das transformações econômicas por que passava o capitalismo brasileiro (RODRIGUES, 1970 ; 1974) e quais as possíveis decorrências disso em termos políticos e sindicais (ALMEIDA, $1975)^{5}$.

Se o período inicial da ditadura e seus primeiros momentos ainda padecem de uma análise mais detalhada e profunda, e o período 1968 e após recebeu análises importantes, mas pontuais; o período pós-1978 acabou por receber uma grande atenção. A partir do ressurgimento de seu movimento com as greves da região industrial do ABC paulista, os trabalhadores voltam à cena política e das preocupações analíticas. Isso produziu trabalhos não só acerca do presente daquele movimento, mas também acerca de seu passado. Nesse sentido, podemos indicar aqueles mais específicos sobre a experiência do ABC (ANTUNES, 1988; ABRAMO, 1999; PARANHOS, 1999) e o papel de setores ligados à Igreja (MARTINS, 1994), bem como sobre a atuação do PCB no movimento operário ao longo do período (SANTANA, 1999). Além disso, existem outras obras que tentam dar conta das articulações entre os setores de esquerda e o movimento operário (FREDERICO, 1987; 1990) e do ressurgimento desse e dos outros movimentos sociais no período (SADER, 1988) ou de sua articulação como o chamado "novo sindicalismo" (MATTOS, 1998; RODRIGUES, 1999; SANTANA, 1999) e sua posterior politização via Partido dos Trabalhadores (MÓISES, 1981), bem como de seu posterior desenvolvimento (BOITO JR., 1991).

\footnotetext{
${ }^{3}$ Para uma visão geral e panorâmica do período pré-golpe e da ditadura, ver Rodrigues (1968) e Erickson (1979). Morel e Mangabeira (1994); Mattos (1998), Santana (1999 e 2001) e Negro (2004), entre outros, fornecem visão de rupturas e continuidades entre o sindicalismo dos dois períodos,

${ }^{4}$ Sobre as greves de 1968, ver, entre outros, Mantega (1978), Santana (1999) e Couto (2003).

${ }^{5} \mathrm{Na}$ mesma linha, mas com outra perspectiva de interpretação, ver Humphrey $(1980 ; 1982)$.
} 
De todo modo, apesar dos variados esforços efetivados ao longo do tempo, esse pode ser considerado um período ainda a ser analisado de forma mais profunda, em termos de conjunto, desvelando mais aspectos da história dos trabalhadores no regime militar. Torna-se cada vez mais premente tornar explicito este "sujeito oculto" ou "ocultado" do período, tentando fazer com que ele apareça em termos de sua "atividade" e não de forma "lacunar".

\section{Visão geral do período}

Muito reduzida e esquematicamente indicaríamos alguns pontos, dentre outros, mais gerais sobre o período no qual os trabalhadores e suas organizações tiveram de lidar com um ambiente ditatorial bastante inóspito aos seus interesses. Uma análise geral das ações dos trabalhadores durante a ditadura indica que uma série de mudanças se estabeleceu, sem que, por isso, possamos deixar de perceber continuidades.

O capitalismo se redefine no país, produzindo mudanças substantivas na produção e no mundo do trabalho, o que traria óbvias alterações na composição das classes trabalhadoras e nos seus destinos.

O Regime Militar buscou redefinir e limitar as ações mais progressistas no seio sindical. Assim, não se tratava de uma mera interdição da vida sindical. Antes, buscou-se uma reestruturação de sua lógica. Mexeuse pouco na morfologia e mais na fisiologia da estrutura sindical existente. Impõe-se e intensifica-se a faceta assistencialista nos sindicatos. É bom lembrar que, longe de um sucesso esmagador, tal estratégia só foi bem sucedida em certos momentos, não sendo capaz de imobilizar tais setores como desejado. E foi exatamente aí que surgiram, dentro e fora da estrutura sindical, possibilidades de ação mais progressista.

Junte-se a isso a mudança no que diz respeito à estabilidade no trabalho, trocada pela contribuição por tempo de serviço, não só facilitando a vida do capital no sentido da intensa rotatividade que lhe era desejável, como impondo dificuldades aos setores militantes em termos de sua organização.

Outro fator interessante que pode ajudar na explicação de muitos pontos, tanto da organização e mobilização dos trabalhadores ao longo de todo o período quanto das reações do regime a elas, está o fato de que, ao trazer para o interior do Estado o controle estrito das possibilidades resultantes das negociações salariais, por conta de sua política econômica de redução da inflação pela via do chamado "arrocho salarial", o regime "politizava" a questão. Uma negociação ou uma greve por aumento de salários se tornava sempre um risco para a política econômica. Isso ficará mais explícito e impactante em fins dos anos de 1970.

Creio que se poderia avançar uma periodização quanto ao movimento dos trabalhadores. Ainda que esquematicamente, pode-se perceber 


\section{ReVistg all pavtg}

\} UM SUJEITO OCULTADO - SANTANA, M. A. \}

três períodos maiores, mesmo que se possa ver dentro deles outras subdivisões. Seriam: um primeiro, imediatamente posterior ao Golpe. De desmanche, mas também de tentativas iniciais de fazer frente à nova realidade. Outro de retomada de iniciativas - resultantes ou não das reações do primeiro momento - de meados dos anos 1960 a meados dos 1970 - com articulações intersindicais, congressos, debates, greves e paralisações etc.... E um último que segue daí até ao final da Ditadura. Cada um deles, à sua maneira, foi marcado por formas de organização, mobilização e ações diferentes. A luta dos trabalhadores, apesar das claras dificuldades, de uma forma ou de outra, não cessou um só momento, não dando tréguas aos patrões e aos militares.

Todo este esforço de "resistir" ao Golpe e à subsequente ditadura não pode obscurecer as ações, no interior do movimento operário e sindical, que visavam ao apoio do regime que se implantou em 1964. Muitos dos interventores, que se perfilavam nas "juntas governativas", eram egressos do seio da categoria e, até mesmo, de setores que atuavam na seara sindical, ainda que com forte traço de oposição aos comunistas em particular, e à aliança comunista-trabalhista em geral. Neste sentido, da mesma forma que um vetor se abria no sentido do enfrentamento ao regime, outro o sustentava no seio das classes trabalhadoras. Tratar os interventores como meros intrusos e estranhos às categorias, colocados ali para sufocá-las, deixa de fora da moldura um conjunto de relações, escolhas e ações que podem auxiliar no entendimento mais amplo da participação dos trabalhadores durante o Regime Militar.

A esquerda passou por sensíveis mudanças de orientação, com claros rebatimentos em suas ações nos sindicatos. Se entramos no período com uma ainda que batida hegemonia do PCB, ao fim do período, um novo setor, vinculado ao PT (OLIVEIRA, 1988; MENEGUELLO, 1989) e à Central Única dos Trabalhadores (CUT), assumirá a hegemonia do sindicalismo passando a orientar a parcela mais significativa, organizada e ativa do movimento (RODRIGUES, 1997). Será a partir de seu ressurgimento na cena política e de sua reorganização nacional que os trabalhadores deram sua forte contribuição, junto a outros setores, para o fim da ditadura no Brasil (VIANNA, 1983; SANTANA, 2003).

\section{O que se precisa ainda fazer}

Dentre as inúmeras possibilidades temáticas ainda a serem exploradas sobre o mundo do trabalho e dos trabalhadores no período, poderia indicar algumas, que têm a ver, obviamente, com muitas das minhas escoIhas. Muitas delas já estão sendo analisadas por pesquisas em curso, as quais, em seus resultados, poderão ser bastante esclarecedoras. 


\section{Revistg all palth}

\} UM SUJEITO OCULTADO - SANTANA, M. A. \}

1) Como se deu concretamente os processos de resistência e/ou apoio ao Golpe em seus primeiros momentos. Que atores e como eles participaram efetivamente do processo? No caso das intervenções sindicais levadas a cabo no pós-Golpe, quais os setores que delas participaram? Que tipo de prática empreenderam concretamente? Qual o alcance efetivo das intervenções, prisões e de pressão sobre os trabalhadores?

2) Os processos de produção capitalista se alteraram no período. Mas como isso se deu concretamente? Como eram? Quem incorporavam na produção? Que tipo de classe operária demandavam?

3) Quais foram as articulações entre as empresas, mesmo deste chamado setor moderno, e o regime? Quais as formas e canais pelas quais isso se deu? Quais os usos políticos e econômicos que lograram fazer?

4) Isso, sem cair na ideia um tanto simples de que só houve ruptura entre as gerações do pré e do pós-64. Assim, apesar destas claras mudanças e novas exigências do capitalismo, como se deram os processos de continuidade de uma geração a outra? De que forma se transmitiu, ressignificou e operou com a experiência operária. Se isso se deu, que canais serviram?

5) Quais as relações estabelecidas, para além das intervenções, entre o Ministério do Trabalho e o movimento sindical? Quais foram suas dinâmicas, agentes, contradições?

6) Tendo em vista a política de "arrocho salarial", como se deram as ações da justiça do trabalho? A que tipo de contradições foi submetida? Como operou ao longo dos variados subperíodos?

7) Como se estruturaram e desenvolveram políticas de formação e cooptação de trabalhadores pelo regime, estabelecidas por empresas e regime?

8) Qual o papel jogado pelas articulações internacionais neste período? Tanto no que tange aos grupos de resistência quando, por exemplo, aos de apoio ao regime? Como se estruturavam e quais os impactos efetivos de políticas, tais como a do Instituto Americano de Desenvolvimento do Sindicalismo Livre (IADESIL), por exemplo?

9) Como se deu ou não a relação entre o movimento dos trabalhadores e os grupos de luta armada? Quais os tipos e formas de articulação e distanciamentos? 


\section{ReVistg all paUtg}

\} UM SUJEITO OCULTADO - SANTANA, M. A. \}

10) Na mesma chave, como se deu ou não a relação entre o movimento dos trabalhadores e os movimentos pela redemocratização?

11) Que papel jogou a Igreja Católica (e/ou demais grupos religiosos) na organização e mobilização dos trabalhadores no período? Como atuaram seus diferentes grupos? Posições assumidas? Impactos e resultados?

12) E, por fim, tendo em vista a tradição de atuação "por dentro" e "por fora" da estrutura sindical, como se deram efetivamente as articulações entre o movimento dos trabalhadores stricto sensu e os demais movimentos sociais?

O que se espera, ao fim de tal investida, é que se consiga contribuir para que a ação dos trabalhadores possa ser realçada, em termos de sua importância, no interior do ambiente ditatorial, escapando de visões já consolidadas sobre o tema que a pensam apenas como lacunar, ausente e deficitária. 


\section{Referências}

AARÃO REIS Foo, D. Questões históricas (exposição). In: M.A. (Org.) As esquerdas e a democracia, Rio de Janeiro, Paz e Terra/Cedec, 1986.

. A maldição do populismo, Linha Direta, n. 330, São Paulo, Partido dos Trabalhadores, set. 1997.

2000.

. Ditadura militar, esquerdas e sociedade. Rio de Janeiro, Jorge Zahar,

. RIDENTI, M.; MOTTA, R. P. S. (Org.). O golpe e a ditadura militar: 40 anos depois, 1964-2004. 1a. ed. Bauru: EDUSC, 2004.

ABRAMO, L. W. O resgate da dignidade: greve metalúrgica e subje-tividade operária. Campinas/São Paulo: Unicamp/Imprensa Oficial, 1999.

ALMEIDA, M. H. T. O sindicato no Brasil: novos problemas, velhas estruturas Debate e crítica, n. 6, São Paulo, 1976.

ANTUNES, R. A rebeldia do trabalho. Campinas: Unicamp/Ensaio. 1988.

ARAUJO, M. P. N.; FICO, C.; MARTINS, I. L.; SOUZA, J. J. V.; QUADRAT, S. V. (Org.). 1964-2004: 40 anos do golpe. Ditadura militar e resistência no Brasil. 01. ed. Rio de Janeiro: 7 Letras/ FAPERJ, 2004.

BOITO Jr., A. (Org.). O sindicalismo brasileiro nos anos 80. Rio de Janeiro: Paz e Terra, 1991.

COUTO, A. M. Greve na Cobrasma: uma historia de luta e resistência, São Paulo: Annablume, 2003.

ERICKSON, K. P. Sindicalismo no processo político no Brasil. São Paulo: Brasiliense, 1979.

FERREIRA, J.; AARÃO REIS Fo, D. (Org.). As esquerdas no Brasil. 3 Vols. Rio de Janeiro, Civilização Brasileira, 2007.

FICO, C. Além do golpe: versões e controvérsias sobre 1964 e a Ditadura Militar. Rio de Janeiro: Record, 2004.

; ARAÚJO, M. P. N. (Org.). 1968 - 40 anos depois: história e memória. $1^{\text {a. }}$ ed. Rio de Janeiro: 7 Letras, 2009.

FIGUEIREDO, A. Democracia ou reformas: alternativas democráticas à crise política (1961-1964). São Paulo: Paz e Terra, 1993.

FREDERICO, C. A esquerda e o movimento operário 1964/1984, v. 1. São Paulo: Novos Rumos, 1987.

A esquerda e o movimento operário 1964/1984, v. 2. Belo Horizonte: Oficina de Livros. 1990.

GORENDER, J. Combate nas trevas. São Paulo, Ática, 1987. 


\section{ReVistg all paUtg}

\} UM SUJEITO OCULTADO - SANTANA, M. A. \}

HUMPHREY, J. As raízes e os desafios do "novo" sindicalismo da indústria automobilística. Estudos Cebrap, n. 26, São Paulo: Cebrap, 1980.

. Fazendo o milagre. Petrópolis: Vozes/Cebrap, 1982.

KRISCHKE, P. J. Brasil: do "milagre" à "abertura". São Paulo: Cortez, 1982.

MANTEGA, G. (Coord.). Greves operárias (1968-1978). Cadernos do Presente, n. 2, Belo Horizonte: Aparte, 1987.

MARTINS, H. S. O Estado e a burocratização do sindicato no Brasil. São Paulo: Hucitec. 1979.

- Igreja e movimento operário no ABC. São Paulo/S. C. do Sul: Hucitec/Pref. S. C. do Sul. 1994.

MATTOS, M. B. Novos e velhos sindicalismos: Rio de Janeiro (1955/1988).

Rio de Janeiro: Vício de Leitura, 1998.

MENEGUELLO, R. PT: a formação de um partido. Rio de Janeiro: Paz e Terra, 1989.

MOISES, J. A. As estratégias do novo sindicalismo, Revista de Cultura Política, Rio de Janeiro: Paz e Terra, 5(6):15-30, 1981.

MOREL, R. L. M.; MANGABEIRA, W. "Velho" e "novo" sindicalismo e uso da justiça do trabalho: um estudo comparativo com trabalhadores da Companhia Siderúrgica Nacional. Dados, vol. 37, n. 1, Rio de Janeiro, 1994.

NEGRO, A. L. Linhas de montagem: o industrialismo nacional-desenvolvimentista e a sindicalização dos trabalhadores, São Paulo: Boitempo, 2004.

OLIVEIRA, I. R. Trabalho e política, Petrópolis: Vozes, 1988.

PARANHOS, K. R. Era uma vez em São Bernardo: o discurso sindical dos metalúrgicos - 1971/1982. Campinas: Editora da Unicamp/Centro de Memória, 1999.

RODRIGUES, I. J. Sindicalismo e política: a trajetória da CUT. São Paulo, Scritta/Fapesp, 1997.

.(Org.) O novo sindicalismo e vinte anos depois. Rodrigues, I. J. (Org.), Petrópolis/São Paulo: Editora Vozes/Educ/Unitrabalho, 1999.

RODRIGUES, J. A. Sindicato e desenvolvimento no Brasil. São Paulo: Difel, 1968.

RODRIGUES, L. M. Industrialização e atitudes operárias. São Paulo: Brasiliense. 1970. 1974. . Trabalhadores, sindicatos e industrialização. São Paulo, Brasiliense,

SADER, E. Quando novos personagens entraram em cena. Rio de Janeiro: Paz e Terra, 1988. 


\section{Revistg all paUtg}

[ UM SUJEITO OCULTADO - SANTANA, M. A. \}

SANTANA, M. A. Entre a ruptura e a continuidade: visões da história do movimento sindical brasileiro. Revista Brasileira de Ciências Sociais, n. 41. São Paulo: ANPOCS, 1999.

. Homens partidos: comunistas e sindicatos no Brasil. São Paulo/Rio de Janeiro: Boitempo/Unirio, 2001.

. "Trabalhadores em movimento: o sindicalismo brasileiro nos anos 1980-1990. In: FERREIRA, J. e DELGADO, L. A. N. Brasil Republicano, vol. 4 - No tempo da ditadura. de Janeiro: Civilização Brasileira, 2003.

SOARES, G. A. D.; D'ARAÚJO, M. C. (Org.). 21 anos de regime militar: balanços e perspectivas. Rio de Janeiro: Fundação Getúlio Vargas, 1994.

TOLEDO, C. N. (Org.) 1964: Visões críticas do golpe - democracia e reformas no populismo. São Paulo: Unicamp, 1997.

VIANNA, L. W. A classe operária e a abertura. São Paulo: Cerifa, 1983.

WEFFORT, F. Participação e conflito industrial: contagem e Osasco, 1968. São Paulo: Cebrap. 1972.

Recebido em 16 de junho de 2014.

Aceito para publicação em 19 de junho de 2014. 